\title{
Autoconceito académico em ambientes virtuais de
}

\section{aprendizagem}

\author{
Academic self-concept in virtual learning environments
}

\author{
José António Marques Moreira \\ Departamento de Educação e Ensino a \\ Distância, Universidade Aberta, Portugal \\ jmoreira@uab.pt
}

\author{
Rita Manuela Barros \\ UNIFAI-ICBAS, Universidade do \\ Porto, Portugal \\ Instituto Piaget, Portugal \\ rbarros@gaia.ipiaget.org
}

\author{
Angélica Maria Monteiro \\ CIIE-FPCEUP, Universidade do \\ Porto, Portugal \\ Instituto Piaget, Portugal \\ amonteiro@gaia.ipiaget.org
}

\begin{abstract}
Resumo Face aos novos desafios que se colocam à educação na atualidade, o recurso a ambientes virtuais de aprendizagem e a análise do seu impacto no desenvolvimento técnico-profissional e psicossocial dos estudantes do ensino superior tem vindo a granjear progressivo interesse pela comunidade científica, nomeadamente no domínio das ciências da educação. A presente investigação tem por objetivo descrever o impacto da utilização dos ambientes online no autoconceito académico de estudantes do ensino superior português $(n=120)$, a partir da análise qualitativa das suas próprias perceções e narrativas, e tendo como referencial de fundo o modelo Community of Inquiry [1] no que concerne à aprendizagem em ambientes virtuais, que servirão de grelha de análise dos dados recolhidos.

Os resultados mostram que estes ambientes virtuais de aprendizagem, ancorados num design centrado na aprendizagem, no desenvolvimento de competências e num modelo pedagógico baseado em princípios como o construtivismo, a autonomia e a interação, podem ter efeitos muito positivos no autoconceito académico dos estudantes do ensino superior, a nível das diferentes dimensões consideradas: Motivação, Orientação para a tarefa, Confiança nas suas capacidades e Relação com os colegas. São discutidas as implicações dos resultados encontrados, quer do ponto de vista de intervenção prática, quer em termos de investigações futuras.
\end{abstract}

Palavras-Chave: autoconceito académico; ambientes virtuais; ensino superior

\begin{abstract}
Regarding the new challenges faced by education today, the use of virtual learning environments and the analysis of their impact in the technical-vocational and psychosocial development in higher education students has conquered a growing interest amongst scientific community, namely in the field of social sciences. The object of this research is to describe the impact of using online environments on the academic self-concept of Portuguese higher education students $(n=120)$, based on the qualitative analysis of their own perceptions and narratives. The background standards of the research are supported by the most relevant theoretical models, with special emphasis on the Community of Inquiry Model [1] as far as learning in virtual environments is concerned, which will be used as an analytical grid for the collected data. The results show that these virtual learning, environments which design is anchored in the development of competences and in learning seen from a pedagogical model based in the principles like constructivism, autonomy and interaction - may have very positive effects on the academic self-concept of higher education students in the various dimensions taken into consideration: Motivation, Orientation for the task, Trust in their own capacities and Relationship with colleagues. The implications of the results are discussed not only from a practical intervention point of view but also in terms of future research.
\end{abstract}

Key Words: academic self-concept; virtual environments; higher education 


\section{Introdução}

As instituições de Ensino Superior (IES) em Portugal enfrentam, na atualidade, desafios inigualáveis, distintos de qualquer outro período da sua existência, os quais se revelam decisivos para a sua sustentabilidade. Em tempos de profundas transformações sociais, económicas e culturais e da rápida evolução das tecnologias de informação e da comunicação (TIC) estas instituições têm-se deparado com a necessidade de se redefinir, no sentido de acompanharem os desafios tecnológicos do mundo pós-moderno e de se ajustarem à mudança de paradigma que subjaz ao Processo de Bolonha [2,3]. Conscientes desta necessidade de mudança, as políticas educativas ao nível do Ensino Superior têm vindo a apresentar iniciativas reformadoras, contemplando nos seus planos estratégicos novas molduras e esquemas de funcionamento, integrando soluções que passam pelas modalidades de eLearning e/ou Blended Learning.

No entanto, poucas são as IES que, efetivamente, promovem alternativas reais de aprendizagem baseadas em Learning Management Systems (LMS). Com efeito, temos vindo a constatar que, em grande parte, estas iniciativas tendem a replicar as políticas até agora vigentes, havendo exemplos do uso dos novos ambientes como uma nova envolvente ou fator de atração, porém, mantendo as práticas usuais de ensino. O exemplo da transposição dos conteúdos programáticos, de suporte em papel ou oral, para domínios informáticos de ambientes virtuais de ensino online ilustra esta tendência para convergir para o "tradicional". Traduz, igualmente, a fragmentação dos saberes, a reestruturação do papel do professor, transformando-o em tutor distante que, muitas vezes, apenas apresenta a proposta de trabalho sem ter participado na sua conceção e desenvolvimento. As "plataformas" são, por vezes, usadas como repositórios de informação onde se oferece material didático aos estudantes e se rececionam tarefas cumpridas ou atividades preenchidas online para maior conforto $\mathrm{e}$ ilusória modernização.

Perante esta constatação, compreende-se a necessidade de o blended learning ser considerado pelas oportunidades que cria para a configuração de comunidades de aprendizagem [4].

Estudos centrados na experiência do estudante, nomeadamente em fatores de (in)sucesso académico ou processos de integração académica em Portugal $[5,6,7]$ têm lançado alguma luz sobre o que significa aprender no ensino superior, mas dão-nos pouca informação acerca do papel que os ambientes virtuais de aprendizagem, ancorados em modelos pedagógicos construtivistas e suportados por LMS, desempenham na promoção do autoconceito académico dos estudantes, constructo considerado fundamental para o desempenho escolar e profissional do estudante do ensino superior $[8,9,10,11$, 12, 13]. Parecendo o autoconceito académico um bom preditor do sucesso escolar, justifica-se, pois, uma atenção mais rigorosa na análise das variáveis pessoais e afetivas do estudante do Ensino Superior [14].

Não obstante existir um certo consenso em torno da definição do constructo, a literatura não apresenta uma definição operacional clara, concisa e que seja universal e unanimemente aceite [15]. Assim, em termos gerais, aceita-se o autoconceito como sendo a perceção que o indivíduo tem de si mesmo. $\mathrm{O}$ autoconceito refere-se ao significado pessoal atribuído à parte cognitivamente organizada da experiência individual. Shavelson, Hubner e Stanton [16] definiram o autoconceito como a perceção que um indivíduo possui de si mesmo, a qual se constrói através de experiências com outros elementos significativos e com base nas atribuições pessoais desenvolvidas pelo sujeito. De acordo com estas definições, o autoconceito é composto por milhares de perceções de importância variada, associadas àquilo que a pessoa é ou julga ser, aos seus interesses e preferências [17]. Byrne [15] considera o autoconceito como a perceção de nós próprios envolvendo as nossas atitudes, sensações e conhecimentos sobre as nossas habilidades, capacidades, aparência e aceitação social. Harter [18] designa o conceito de si próprio como, simultaneamente, um constructo multidimensional, ao aceitar como indicadores deste os juízos de auto-avaliação em várias áreas da existência, e como constructo global, ao enfatizar a importância da autoestima global, enquanto dimensão independente.

A maior parte dos estudos sobre o autoconceito sustenta-se numa estrutura multidimensional do constructo $[15,16,18,19,20,21]$, perspetivando-o de forma hierarquicamente organizada, estruturada e multifacetada, sublinhando na essência avaliativa a sua natureza desenvolvimental, designadamente a sua estabilidade relativa [22, 23, 24]. Segundo Shavelson et al. [16], o autoconceito geral pode ser dividido em duas dimensões principais: a dimensão escolar ou académica e a dimensão não escolar ou não académica que, por sua vez, se subdividem em componentes mais específicas.

Mais recentemente, Peixoto e Almeida [25], ao analisarem a estrutura hierárquica do autoconceito em adolescentes, apresentam um modelo que o subdivide em quatro fatores de ordem superior: autoconceito de apresentação, autoconceito social, autoconceito académico verbal e autoconceito académico matemático. Este estudo vai ao encontro da proposta de Byrne [15], quando insiste na necessidade de um esforço teórico, no 
sentido de conhecer aprofundadamente as propriedades estruturais do autoconceito, assim como das suas relações com outras variáveis.

Relativamente ao domínio académico, o autoconceito parece ser mais bem representado por duas dimensões de ordem superior, designadamente pelo autoconceito académico verbal e pelo autoconceito académico matemático [25]. O autoconceito académico diz respeito à imagem que o indivíduo desenvolve e tem de si como sujeito envolvido num determinado processo de escolarização e de aprendizagem [26]. Lima e Seco [27] e Simões e Serra [10] salientam que o autoconceito académico se refere às perceções e avaliações das competências que o indivíduo julga possuir para cumprir as exigências inerentes ao processo escolar em que se encontra envolvido, em comparação com outros indivíduos do seu grupo de referência.

Estudos diferenciais realizados em contexto universitário [28] evidenciam diferenças no autoconceito académico, com vantagem para os estudantes no início da formação superior. Neste domínio, é através de um processo de comparação interpessoal que se forma o autoconceito de um estudante. Por outras palavras, o seu autoconceito, nomeadamente no que concerne a esta dimensão, não depende apenas do seu rendimento, pensado em termos absolutos, mas depende, igualmente, da comparação dos seus resultados com os resultados dos outros estudantes [10]. Assim, as características do contexto de aprendizagem assumem um papel deveras importante no desenvolvimento do conceito de si e, em particular, no conceito de si próprio em questões de aprendizagem. Esta tem sido uma das facetas do autoconceito com relevância particular, quer pelo seu valor intrínseco, quer pelo seu papel mediador na relação entre outras variáveis, tendo vindo a ser perspetivada como uma das variáveis psicológicas que mais podem contribuir para a compreensão do processo educativo. De facto, o autoconceito é uma variável a considerar no estudo do processo e resultados da aprendizagem/rendimento escolar porque, como observam Chapman e Boersma [29], um autoconceito escolar positivo, embora não seja em si mesmo um fator suficiente na determinação do sucesso escolar, parece constituir uma condição necessária para um desempenho escolar médio.

Estudantes com um autoconceito elevado evidenciam confiança na sua competência como estudantes, otimismo em relação ao seu futuro e estabelecem objetivos realistas [30]. Em contrapartida, é sabido que aqueles estudantes que revelam um autoconceito negativo manifestam expectativas negativas e desenvolvem, com frequência, a ideia de que são incapazes de aprender. As perceções e avaliações negativas acerca das suas capacidades são capazes de determinar de uma forma decisiva o seu comportamento. De um modo geral, as tarefas escolares são abordadas sem confiança e com desprazer. Os sentimentos de desencorajamento e frustração são habituais e podem ser até acompanhados de depressão e de ansiedade. Isto, de facto, é válido se o estudante atribui a esta faceta do autoconceito uma importância muito grande e toma os desempenhos escolares como base de caracterização do seu valor pessoal. Simões e Serra [10] corroboram esta posição, defendendo que os estudantes com dificuldades de aprendizagem podem ser envolvidos em círculos viciosos em que o fracasso escolar e as características afetivas negativas são mutuamente reforçantes. Os professores influenciam o desenvolvimento do autoconceito académico do estudante, na medida em que comunicam as suas expectativas em relação ao seu desempenho, podendo influenciá-los de uma maneira negativa ou positiva. $\mathrm{O}$ estudo de Urhahne, Chao, Florineth, Luttenberger e Paechter [31] sublinha o erro de julgamento dos professores em relação aos estudantes que subestimam o seu desempenho na área da matemática, os quais apresentam baixas expectativas de sucesso, baixo autoconceito académico e níveis mais elevados de ansiedade. Este erro de julgamento não se confina à expectativa de desempenho em si mesmo, mas atinge traços afetivos e motivacionais dos estudantes.

Para além da influência dos professores, a relação com os pares é igualmente importante, visto que é através de um processo de comparação interpessoal que se forma o autoconceito do estudante. De acordo com Burns [32] e Bento [33], um indivíduo desenvolverá um autoconceito positivo desde que obtenha aceitação e aprovação por aquilo que é e tenha consciência deste facto.

Assim, com o objetivo de analisar as perceções relativamente ao impacto e aos efeitos dum ambiente e de um modelo pedagógico online no autoconceito académico dos estudantes do ensino superior, em dimensões como a motivação, a orientação para as tarefas, a confiança nas suas capacidades ou a relação com os pares, desenvolvemos o presente trabalho.

Como quadro conceptual tomámos o modelo de comunidades de investigação de Garrison, Anderson e Archer [1] (e.g., Community of Inquiry) e Garrison e Anderson [34]. Este modelo é geralmente considerado como uma das propostas mais completas e integradas, no que se refere ao papel do professor nestes ambientes educativos. A ideia subjacente ao modelo é que uma comunidade de investigação educativa é constituída por um grupo de indivíduos que, em colaboração, pratica um discurso intencionalmente crítico e uma reflexão, no sentido de construir um significado pessoal e confirmar o entendimento mútuo. É um modelo que assenta em três dimensões de base: a dimensão cognitiva, social e docente. A presença cognitiva, segundo Garrison e Anderson [34], corresponde ao que os estudantes podem construir e conferir significado, a partir de uma reflexão 
sustentada e do discurso crítico; trata-se de um processo de pensamento crítico. A presença social corresponde à capacidade dos membros de uma comunidade se projetarem socialmente e emocionalmente através do meio de comunicação em uso. Assenta na criação de relações afetivas entre os participantes, enquanto facilitadoras da presença cognitiva. Por último, a presença de ensino é definida também pelos autores como sendo a direção, o design, a facilitação da presença cognitiva e da presença social, no sentido da realização dos resultados de aprendizagem significativos [34]. A presença docente é um elemento de base, na medida em que the cabe a tarefa de implementar e desenvolver a comunidade e orientar a aprendizagem dos seus membros. Esta presença docente faz sentido, por um lado, para gerar um ambiente social facilitador do pensamento crítico e, por outro, para orientar a aquisição de informação e a construção do conhecimento. A existência destes elementos e das suas inter-relações são cruciais para o sucesso das experiências educativas.

Para Garrison e Anderson [34], o modelo assenta numa perspetiva construtivista da aprendizagem e a construção do conhecimento individual deve-se, em grande medida, ao ambiente social. Ou seja, um ambiente que favoreça uma diversidade de perspetivas pode promover a investigação, a crítica e a criatividade. Em ambiente colaborativo, o indivíduo assume o dever de dar sentido à sua experiência educativa, responsabilizando-se pelo controlo da sua aprendizagem, através da negociação de significados com o grupo.

Em síntese, a nossa investigação pretende perspetivar possíveis cenários e designs alternativos de aprendizagem, no domínio da pedagogia no Ensino Superior, estudando o efeito deste modelo no autoconceito académico dos estudantes, nomeadamente, no que diz respeito à motivação, à orientação para as tarefas, à confiança nas próprias capacidades, relação com os pares, bem como de exploração e aprofundamento das aprendizagens, com reflexo nos resultados esperados.

\section{Aspetos metodológicos}

Neste estudo pretendemos, fundamentalmente, e como já referido, analisar a perceção do impacto dos ambientes virtuais de aprendizagem e de um modelo pedagógico online no autoconceito académico de estudantes do Ensino Superior. A natureza da indagação levou-nos a considerar pertinente uma abordagem qualitativa, em que o discurso direto se submete a uma lógica interpretativa, que, ao enquadrar e explicitar a perceção dos estudantes questionados, pretende dar conta de como estes percecionam os efeitos do ambiente virtual no seu autoconceito académico. Situando-nos, portanto, num quadro de um paradigma não positivista e interpretativo, de natureza fenomenológica e ideográfica [35], recorremos, nesta investigação, a uma metodologia de cariz qualitativo que põe a tónica na revalorização da "pessoa" como sujeito de conhecimento, capaz de refletir, de racionalizar, de comunicar e de interagir [36].

Com o intuito de suscitar a emergência de dados referentes ao estudo, recorremos a uma técnica de investigação capaz de codificar as declarações semilivres e aparentemente desordenadas: a análise de conteúdo [37, $38,39,40,41,42]$.

Iniciámos a análise de conteúdo procedendo à leitura flutuante da totalidade das respostas ao inquérito com o intuito de alinhar os temas comuns e de detetar particularidades em função da individualidade dos casos. Posteriormente, iniciámos o processo de sistematização da categorização emergente, procurando respeitar a regra de exaustividade defendida por Bardin [39], que considera todos os elementos do corpus. Tendo em conta todas as respostas para a categorização e comparação do conteúdo, separámos as unidades de registo do corpus em parágrafos e numerámo-las sequencialmente em função do alinhamento das respostas. A análise foi feita em função do quadro de categorias definido, combinando a emergência de novos dados já sugeridos pelo quadro conceptual e pela revisão da literatura. Com o intuito de organizar a informação de forma percetível, optámos por codificar os dados baseando-nos em apenas três letras que derivam, basicamente, das iniciais, ou das três primeiras letras da palavra ou do conjunto de três letras significativas.

A nossa amostra foi constituída por um grupo de 120 estudantes de uma Escola Superior de Educação dos cursos de Licenciatura em Educação Básica e Educação Física, com 70 e 50 estudantes, respetivamente.

$\mathrm{O}$ instrumento que serviu de base à recolha de dados foi um inquérito por questionário distribuído presencialmente. Tendo em conta o âmbito e o objetivo do estudo, bem como a análise documental de alguns normativos relevantes no contexto em estudo, baseámonos no Self Concept as a Learner Scale (SCAL) desenvolvido por Waetjen, em 1972, posteriormente adaptado por Veiga [43] à população portuguesa, para construir o nosso instrumento. As quatro dimensões que constituem o SCAL foram aquelas que definimos para o nosso instrumento. A primeira - Motivação (MOT) - faz referência às perceções que o estudante tem de si próprio, relativamente ao gosto e interesse pelas e-atividades desenvolvidas no ambiente virtual de aprendizagem; a segunda - Orientação para a Tarefa (OPT) - avalia o cuidado com que o estudante realiza as e-atividades no ambiente virtual, referindo-se, essencialmente, ao esforço para fazer bem as atividades indicadas; a terceira Confiança nas Capacidades (CNC) - avalia a confiança 
que o estudante tem nas suas capacidades para desenvolver as atividades online e na expressão das suas ideias nas salas de aula virtuais; e a quarta Relação com os Colegas (RCC) relaciona-se com a sua integração na comunidade virtual de aprendizagem e com a perceção de confiança recebida da comunidade. Com base nestas categorias, definimos uma série de questões abertas que constituíram o corpo do inquérito. A informação proveniente dos inquéritos será apresentada em quadros, com o objetivo de exemplificar a relevância de algumas das suas opiniões, contendo esses quadros a codificação referente ao número $(\mathrm{N})$ de estudante $(\mathrm{E})$, o número da unidade de registo e o registo com excertos do seu discurso.

\section{Design do ambiente educativo}

Antes de conceber o design do ambiente educativo da unidade curricular (UC) intitulada Dinâmicas do Mundo Contemporâneo e Evolução do Espaço Português, foram definidos alguns princípios que podem ser generalizados para ambientes online, nomeadamente: (i) o design deve centrar-se na aprendizagem, visando atingir objetivos específicos, realizáveis e mensuráveis; (ii) deve centrar-se no desempenho ou realizações significativas; (iii) deve permitir que os resultados sejam medidos de uma forma fiável e válida, desenvolvendo os instrumentos necessários à avaliação do desempenho; e (iv) deve ser empírico e autorregulável.

Para além destes princípios, foram, igualmente, considerados alguns componentes fundamentais para $\mathrm{o}$ adequado desenvolvimento do processo de ensinoaprendizagem online. Em primeiro lugar, na UC foi produzido um guia pedagógico que serviu de principal referência para o estudante relativamente ao conteúdo, à estrutura e às atividades. Procurou-se estabelecer, no seu design, uma articulação horizontal entre todos os seus elementos e uma articulação vertical inteligível. Também foi necessário descrever claramente os objetivos de aprendizagem, definidos segundo os resultados previstos, e não apenas centrados no conteúdo. $\mathrm{O}$ guia pedagógico incluiu os recursos de aprendizagem que os estudantes deviam utilizar (e.g., livros e artigos que deviam ler e aqueles que deviam consultar a fim de aprofundarem os seus conhecimentos; vídeos, imagens e sítios na Internet relacionados com os temas de estudo), as atividades a realizar e os critérios de avaliação. Note-se que, apesar das orientações específicas do guia, a sua aplicação foi flexível. Os princípios de flexibilidade e adaptabilidade considerados indispensáveis em ambientes construtivistas por Garrison e Anderson [34] estiveram sempre presentes.

Em segundo lugar, foram disponibilizados no LMS recursos diversificados relacionados com os objetivos de aprendizagem. Artigos versando os temas discutidos e conteúdos multimédia online (áudio e vídeo) foram colocados à disposição dos estudantes, visando motivar e criar um vínculo entre os estudantes e o professor.

Em terceiro lugar, houve uma enorme preocupação com o desenvolvimento das tarefas a realizar pelos estudantes, focando todo o processo nos problemas que os estudantes deviam resolver e, consequentemente, desenvolvendo experiências de aprendizagem (individuais e colaborativas).

Em quarto lugar, a dinamização das salas de aula virtuais (fóruns), através da comunicação assíncrona, foi um elemento determinante e estruturante de todo o processo educativo. Como resultado, procurou-se promover a comunicação assíncrona nas salas de aula virtuais em todos os tópicos das unidades curriculares, através de três tipos de padrões de comunicação: (i) interação do(s) estudante(s)-conteúdo, (ii) interação do(s) estudante(s)-professor e (iii) interação do(s) estudante(s)estudante(s). $\mathrm{O}$ fórum foi o meio privilegiado de comunicação para permitir a realização dos debates entre os estudantes e o professor.

\section{Análise}

Face aos novos desafios que se colocam à educação na atualidade, o recurso a ambientes virtuais de aprendizagem e a análise do seu impacto no desenvolvimento técnico-profissional e psicossocial dos estudantes do ensino superior tem vindo a granjear progressivo interesse pela comunidade científica, nomeadamente no domínio das ciências da educação. Com o intuito de compreender o impacto da utilização destes ambientes no autoconceito académico de estudantes do Ensino Superior, procedemos, pois, à análise das suas perceções. Ainda antes de passarmos à análise dos resultados, pensamos que é necessário fazer referência a alguns aspetos que consideramos importantes. Em primeiro lugar, deve dizer-se que o estudo que aqui apresentamos foi realizado no âmbito de uma investigação mais abrangente que se debruçou sobre o autoconceito, não apenas na sua dimensão académica referente às perceções e avaliações das competências que o indivíduo julga possuir para cumprir as exigências inerentes ao processo escolar, mas também nas diferentes dimensões e categorias que o compõem. E, em segundo lugar, é de referir que a análise dos dados emergentes obedeceu a uma lógica de funcionamento baseada na alternância de duas fases. Numa primeira fase foi realizada uma análise vertical de cada um dos questionários e na segunda procedemos a uma análise horizontal ou comparativa com recurso ao método da "análise comparativa constante" [44] com o intuito de identificar aspetos comuns e distintivos das representações e perceções destes estudantes. Para o 
efeito apresentaremos a informação em quadros, com o objetivo de exemplificar a relevância de algumas das suas opiniões, contendo esses quadros a codificação referente ao número de estudante (EST) e turma do estudante (Educação Básica - EB ou Educação Física - EF), o número da unidade de registo (UR), e o registo com excertos do seu discurso. Pensamos que a escolha deste modelo organizativo da informação, que permite estudar as perceções dos estudantes de uma forma sistemática e analítica, permitirá uma mais adequada visualização do quadro geral representativo das suas conceções.

Assim, na primeira categoria, Motivação, com cento e vinte registos que comportam as referências às perceções que os estudantes têm de si próprios, relativamente ao gosto e interesse pela metodologia e pelas e-atividades desenvolvidas no ambiente virtual de aprendizagem, a classificação das unidades de registo repartiram-se pelas frequências de Motivante (+) e Pouco ou Nada Motivante
(-). A primeira, Motivante, foi aquela que recebeu a maioria das referências, cento e dezanove registos, o que sugere, claramente, que estes estudantes consideram que as atividades desenvolvidas no ambiente virtual de aprendizagem foram extremamente motivadoras; a segunda, Pouco ou Nada Motivante, com apenas um registo, supostamente traduz a incapacidade destes ambientes na adequação da formação à realidade profissional.

Relativamente às representações dos estudantes do curso de Educação Básica, verificamos nesta área sessenta e nove registos de tendência positiva $(+)$ e apenas um de tendência negativa (-), embora este último registo se refira a questões motivacionais relacionadas não com a $\mathrm{UC}$, mas com expectativas relativamente ao seu futuro profissional. Assim, todos os estudantes consideraram que este ambiente constituiu um forte elemento de motivação.

\begin{tabular}{|c|c|c|c|}
\hline EST & UR & S & Registo \\
\hline EB1 & 1 & + & $\begin{array}{l}\text { O início da UC foi complicado e as expectativas não eram muito boas. Mas, após o primeiro módulo, a minha } \\
\text { forma de ver o ensino online mudou completamente. A discussão nos fóruns dá-nos vontade de sempre que } \\
\text { ligamos o computador digitar a página do Moodle. Toda a metodologia e a interação do próprio docente } \\
\text { contribuíram para uma motivação extra. }\end{array}$ \\
\hline EB14 & 56 & + & $\begin{array}{l}\text { De facto, o ambiente utilizado teve bastante influência na minha motivação para a UC, não só por permitir a } \\
\text { troca de opiniões e argumentos nas salas de aula virtuais, mas, essencialmente, porque o próprio professor } \\
\text { soube retirar o máximo das ideias de cada aluno, pela forma "provocadora" de diálogo que usou. }\end{array}$ \\
\hline EB34 & 136 & + & $\begin{array}{l}\text { Esta "coisa" da Educação à Distância revelou-se para mim muito estimulante. Permitiu-me, de acordo com as } \\
\text { orientações dadas pelo professor, investigar, recolher, analisar e selecionar informação que me possibilitaram } \\
\text { cumprir as tarefas propostas, "acordando" capacidades há muito "adormecidas" e que precisavam de ser } \\
\text { "abanadas". Permitiu-me, também, gerir o meu tempo de uma forma mais eficaz, conciliando a minha } \\
\text { atividade profissional com a académica. }\end{array}$ \\
\hline
\end{tabular}

Quadro 1 : Motivação - Estudantes do Curso de Educação Básica.

Como podemos ver na primeira unidade de registo exemplificativa, o estudante - EB1 -, que mostrava algum receio relativamente à eficácia dos ambientes online, refere que, após o início das aulas da UC, mudou completamente de ideia e que ficou, inclusive, "viciada" no ambiente. E termina dizendo que para esta mudança de opinião contribuiu muito a ação do professor e da metodologia utilizada no ambiente virtual.

Outra estudante - EB10 - tem uma opinião idêntica, referindo também: "No início da UC, não tinha grande interesse em muitas das temáticas abordadas nas aulas, pois sou um pouco distraida e desinteressada em algumas coisas que me rodeiam, mas durante as aulas online essa perceção mudou, pois cheguei à conclusão que é necessário termos conhecimento dos factos que nos rodeiam e isso deu-me bastante motivação e incentivo para a UC e para discutir com o professor e os meus colegas as temáticas abordadas na plataforma. Posso neste momento dizer que gostei do ambiente virtual, da forma como os conteúdos programáticos foram abordados e do facto de estes serem lecionados de uma forma não tradicional, mas sim através das novas tecnologias (Moodle), e isso motivou-me para ir às aulas, para trocar ideias com os elementos presentes e para estar mais atenta aos factos que me rodeiam, não só para as aulas mas também para a minha vida pessoal $e$ profissional futura. E saber que a minha opinião, embora não seja muito importante fora da sala de aula, dentro dela não era insignificante, pois contava, pelo menos, para uma melhor nota" (UR40).

Por sua vez, a estudante - EB14 -, como podemos ver na segunda unidade de registo exemplificativa (UR56), considera que não foi só a forma como o ambiente virtual de aprendizagem estava organizado que contribuiu para o aumento da sua motivação, mas foi também o próprio 
professor que se assumiu, nas suas palavras, como um "provocador" e procurou estimular os estudantes a participar nos diferentes espaços de conversação criados no ambiente virtual.

Com efeito, uma das potencialidades destes ambientes virtuais de aprendizagem prende-se com a interatividade e interação, que se pode estabelecer entre os diferentes participantes. E neste processo de interação, o professor é o responsável por identificar os conhecimentos relevantes, propor experiências que levem ao discurso crítico e à reflexão, diagnosticar e avaliar os resultados de aprendizagem, sendo que o e-Learning exige uma maior atenção ao equilíbrio entre o controlo e a responsabilidade [34].

Por sua vez, a estudante - EB34 -, na terceira unidade de registo exemplificativa, referindo-se à educação a distância como uma "coisa", considera que este ambiente virtual se revelou muito estimulante, porque lhe permitiu, de acordo com as orientações do professor, investigar, recolher, analisar e selecionar informação que lhe possibilitaram cumprir as e-atividades propostas com sucesso.

Esta abordagem é extremamente importante, porque permite que o estudante esteja no centro da sua aprendizagem e tenha uma participação ativa construindo o seu próprio conhecimento [45]. Há uma nova relação entre o conhecimento e a aprendizagem, como se depreende das palavras da estudante EB38: “(...) Os trabalhos realizados no Moodle, apesar de muito exigentes, permitiram-me aprender bastante, porque fui obrigada a pesquisar sozinha" (UR152).

É, pois, uma abordagem que encoraja e aceita a autonomia e iniciativa dos estudantes; que encoraja os estudantes a dialogar com o professor e entre si; que os encoraja a resolverem os problemas e perguntarem uns aos outros a solução; que os estimula a assumir responsabilidades e que estimula a discussão e que mantém a curiosidade do estudante [46]. Também o estudante EB37 destaca a importância do papel do professor, referindo: "O professor usou métodos que nos cativaram muito; os temas discutidos nas aulas atraíram a nossa atenção como um íman atrai os metais $e$, de repente, estávamos todos colados aos temas, tornando-se motivo de conversa não só na sala de aula virtual, mas também fora da sala, noutras redes sociais” (UR141).

Perante esta abordagem, o professor deve estar consciente de que não se trata apenas de dominar um qualquer instrumento ou um novo sistema de representação de conhecimento, mas sim de uma nova cultura de aprendizagem. Isto pressupõe que os professores, mais do que transmitir informação, promovam competências nos seus estudantes, de procura, seleção e interpretação da informação disponível. Nesta sociedade em rede, com as alterações que comporta na aprendizagem e na construção do conhecimento, o professor deve assumir-se, pois, como mediador e facilitador, proporcionando as ajudas educativas adequadas a uma aprendizagem construtiva do estudante. A este respeito, o estudante EB23 destaca que sempre esteve motivado desde o início das aulas até ao fim. Explica ele: "A forma como o professor estruturou os conteúdos na plataforma com referência a obras de arte, filmes, documentários, espaços de discussão e reflexão, onde pude aprender com os meus colegas e com o professor, que teve sempre uma presença assídua a dar resposta e a orientar os alunos no seu processo de aprendizagem, foi muito motivante para mim" (UR92).

Relativamente às perceções dos estudantes do curso de Educação Física, verificamos que os cinquenta registos, todos de tendência positiva $(+)$, são muito idênticos aos estudantes do curso de Educação Básica, também eles considerando este ambiente extremamente motivante.

\begin{tabular}{|l|l|c|l|}
\hline EST & UR & S & Registo \\
\hline EF75 & 300 & + & $\begin{array}{l}\text { O ambiente online manifestamente “abriu-me o gosto à disciplina”. O “à-vontade” com que nos deparamos, } \\
\text { desde a situação das faltas que não eram marcadas, a liberdade de expressão em respeito com outros } \\
\text { intervenientes e a relação docente-alunos contribuíram para que tenha gostado bastante de participar nos } \\
\text { módulos que foram lecionados. }\end{array}$ \\
\hline EF101 & 404 & + & $\begin{array}{l}\text { Motivou-me bastante o ambiente utilizado para a aprendizagem de certos temas; a visualização de filmes } \\
\text { trouxe-me mais interesse para a aprendizagem dos temas vistos, ajudavam a olhar para o problema de outra } \\
\text { forma. }\end{array}$ \\
\hline
\end{tabular}

Quadro 2 : Motivação - Estudantes do Curso de Educação Física.

Como podemos ver na primeira unidade de registo exemplificativa, o estudante - EB75 - refere que o ambiente virtual de aprendizagem lhe "abriu o gosto pela UC”. A relação estabelecida entre os estudantes e o professor, a liberdade de expressão que sentiu nas salas de aula virtuais, a ausência de um regime de faltas foram algumas das razões que apontou para justificar a sua motivação. 
Outros estudantes - EF83, EF87, EF110, E115 - têm uma opinião idêntica, referindo também: "Senti-me motivada pelo facto de não só as temáticas serem de especial interesse e preocupação pessoal, mas também pelo facto de o ambiente utilizado ter permitido expor ideias, pensamentos, gostos, desabafos, críticas, desapontamentos e sugestões que de outra forma não poderiam ser expostos publicamente" (UR332).

"Sem dúvida que o ambiente online me motivou para o estudo e pesquisa de cada tema abordado” (UR381).

"A metodologia usada nesta disciplina foi, na minha opinião, muito positiva! Adorei trabalhar no Moodle, pois assim cada um de nós deu a sua opinião sobre cada tema abordado e debatido na aula" (UR440).

Por sua vez, a estudante - EF101 -, como podemos ver na segunda unidade de registo exemplificativa (UR56), considera que se sentiu bastante motivada, devido também à utilização de objetos de aprendizagem audiovisuais, porque permitiram olhar para algumas questões de uma outra perspetiva. Com efeito, observados de uma determinada ótica e com objetivos e tarefas bem definidas, estes objetos de aprendizagem audiovisuais podem tornar-se em algo mais do que um momento de emoção e diversão, podendo converter-se numa experiência viva e interessante, que ajuda os estudantes a alargarem conceitos, a pensarem e a confrontarem-se criticamente com outras realidades, a interiorizarem valores que se dispersariam numa incerta pesquisa e a agarrar ideias que não cabem dentro de definições, nem se compreendem totalmente através da leitura de um texto [47]. No cerne dessa atitude está, pois, a forma como o professor encara essa ferramenta, a capacidade que tem em integrá-la de forma oportuna num conjunto de outras estratégias e recursos didáticos ou no aproveitamento que dela retira como método de abordagem ao próprio tema [48]. Quando mais oportuno e útil for o recurso audiovisual, quanto mais os estudantes sentirem que têm nele uma oportunidade de compreender melhor as questões em estudo, de completar um puzzle que sem o vídeo ficaria inacabado, melhor será a sua adesão à metodologia [49].

Com efeito, estes objetos de aprendizagem audiovisuais, e como referem vários autores [50, 51, 52, 53] apresentam um enorme potencial como tecnologia de instrução. Amaral refere, inclusive, que o vídeo digital vai ser "el medio de comunicación más potente de este siglo, porque él abre las puertas, de un modo muy especial, para la alfabetización audiovisual permanente, posibilita y fomenta en los espectadores la capacidad de producir, analizar y modificar sus propios mensajes", p. 11 [54].

Perante esta realidade, e usando os recursos audiovisuais uma linguagem tão próxima daquela que é utilizada diariamente, faz todo o sentido apropriarmo-nos do seu potencial comunicativo, trazendo-os para as salas de aula virtuais para, de um modo consciente, os tornar em ferramentas de mediação pedagógica capazes de contribuirem para a grande odisseia da escola contemporânea que se vai ancorando em perspetivas socioconstrutivistas e que coloca o estudante no centro do processo pedagógico [48]. A opinião da estudante EF106 revela-nos que, efetivamente, faz sentido a apropriação desse potencial comunicativo, ao afirmar: "A metodologia utilizada foi a minha grande motivação, pois visualizámos filmes muito interessantes e as aulas online foram muito enriquecedoras" (UR124).

O corpo de unidades de registo pertencentes a esta categoria mostram-nos assim, claramente, que os estudantes consideram que o ambiente online "desenhado" pelo professor foi um fator motivacional determinante para o seu desempenho escolar. Ao destacarem a presença constante do professor nos diferentes espaços de comunicação do ambiente e os diferentes papéis assumidos (motivador, mediador, moderador...), ao salientarem a interação social existente entre estudantes e professor e entre pares e ao assumirem que este ambiente gerou discussões e conflitos cognitivos estimulantes, os estudantes indiciam que o modelo pedagógico proposto, assente nas dimensões cognitiva, social e docente, cumpriu o seu principal objetivo, pois na realidade pensamos que nesta UC emergiu uma comunidade de investigação educativa tal como Garrison, Anderson e Archer [1] a definem. Na verdade, a estrutura teórica deste modelo representa um processo de criação de aprendizagem profunda e significativa, através da experiência colaborativa e construtivista. Tal é conseguido através do desenvolvimento dos três elementos interdependentes, embora o crescimento cognitivo dependa fortemente da interação social e do discurso, para partilhar opiniões e trocar informações [55].

Relativamente à segunda categoria, Orientação Para a Tarefa, também com cento e vinte registos, referente às perceções que os estudantes têm de si próprios, no que concerne ao cuidado com que realizam as e-atividades no ambiente virtual, a classificação das unidades de registo mostra apenas perceções de tendência positiva $(+)$, o que revela que os estudantes, de ambos os cursos, consideram que se esforçaram por cumprir as tarefas solicitadas pelo professor no ambiente virtual. Para além disso, os resultados indicam-nos que estes consideram que o LMS é uma ferramenta que pode facilitar a organização e a gestão do tempo despendido na realização das $e$ atividades. 


\begin{tabular}{|c|c|c|c|}
\hline EST & UR & S & Registo \\
\hline EB2 & 6 & + & $\begin{array}{l}\text { A realização das tarefas na plataforma (Moodle), na minha opinião, é a melhor forma de realizar tarefas, pois } \\
\text { cada um gere o tempo como quer; as tarefas eram realizadas onde quiséssemos e onde nos sentíssemos } \\
\text { melhor; no meu caso eram em casa, onde as realizava com calma, com tempo e mais paciência. }\end{array}$ \\
\hline
\end{tabular}

Quadro 3 : Orientação para a Tarefa - Estudantes do Curso de Educação Básica.

Como podemos ver na primeira unidade de registo exemplificativa, o estudante EB2 refere que o LMS é um meio muito útil para realizar as tarefas solicitadas, porque permite que o estudante faça uma gestão adequada do seu tempo e permite a sua realização no espaço que mais the apraz.

A maioria dos testemunhos recolhidos sublinha estas vantagens do ponto de vista da gestão do tempo e do espaço na realização das e-atividades, referindo:

EB12 - "O facto de termos realizado as nossas tarefas a partir do Moodle facilitou em muito a organização e a gestão do tempo gasto nessas tarefas, pois usei o tempo de que necessitei para as fazer em casa sem grandes pressões, e na altura que mais me convinha, sem estar sujeita a tempos impostos" (UR42).
EB19 - "A possibilidade de poder elaborar e enviar os trabalhos pela plataforma com um tempo definido possibilitou-me gerir melhor o meu tempo e ver as minhas prioridades" (UR74).

EB23 - "Acho que a utilização da plataforma permitiu uma boa organização das atividades. A plataforma permitiu-nos ter tudo planeado (horas e dia) para a entrega das atividades" (UR86).

EB28 - "A metodologia online usada permitiu-me organizar o meu tempo e realizar as atividades de acordo com a minha disponibilidade horária” (UR106).

Também os estudantes do curso de Educação Física apresentam perceções semelhantes, colocando a tónica na metodologia online que lhes possibilitou organizar e gerir as tarefas de forma adequada.

\begin{tabular}{|l|c|c|c|}
\hline EST & UR & S & Registo \\
\hline EF71 & 285 & + & A metodologia utilizada permitiu-me organizar e gerir as atividades da UC de uma maneira mais adequada. \\
\hline
\end{tabular}

Quadro 4: Orientação para a Tarefa - Estudantes do Curso de Educação Física

Com efeito, como podemos ver na unidade de registo exemplificativa (UR 285), o estudante considera que a metodologia utilizada lhe permitiu organizar e gerir muito bem as tarefas da UC. É essa também a opinião dos estudantes EF74 e EF91, ao afirmarem que:

“(...) A metodologia online ajudou-me a organizar melhor os temas abordados pelo professor" (UR297).

"Nas atividades online consegui perfeitamente gerir $o$ tempo que me foi dado para realizar as atividades propostas. Funcionou muito bem" (UR365).

Neste contexto, não podemos deixar de salientar que o recurso a ambientes online se justifica também pelo aumento da oportunidade do acesso e flexibilidade, uma vez que, atualmente, há estudantes mais velhos, com compromissos familiares e profissionais, que encaram estes ambientes como uma solução muito interessante para conciliar todas as atividades onde estão envolvidos [56]. Como salienta a estudante EF93:

“(...) Permitiu-me, por outro lado, gerir o meu tempo de uma forma mais eficaz, conciliando a minha atividade académica com a minha profissão, enriquecendo uma e outra” (UR373).

Outros testemunhos sublinham que, para além da metodologia, o professor também teve um papel determinante na orientação para as tarefas, porque organizou a UC de uma forma equilibrada, o que lhes permitiu terem tempo suficiente para realizar as $e$ atividades propostas. Essa ideia é-nos transmitida pela estudante EF96:

"A forma como o docente organizou a disciplina facilitou a minha orientação para as tarefas" (U385).

Como já foi referido, ao elaborar o design do ambiente educativo, houve a preocupação de elaborar um guia pedagógico semestral, uma referência para o estudante relativamente ao conteúdo, à estrutura, aos recursos, às e-atividades a realizar e aos critérios de avaliação, e este parece ter sido determinante na adequada gestão do tempo que os estudantes referiram.

A terceira categoria, Confiança nas Capacidades, com cento e vinte registos, avalia a confiança que o estudante tem nas suas capacidades para desenvolver as e-atividades online e na expressão das suas ideias nas 
salas de aula virtuais. A classificação das unidades de registo, repartiram-se pelas frequências de Confiante $(+)$ e Pouco ou Nada Confiante (-). A primeira, Confiante, foi aquela que recebeu a maioria das referências, cento e quinze registos, o que sugere, declaradamente, que o ambiente de aprendizagem tornou alguns destes estudantes mais confiantes nas suas capacidades; a segunda, Pouco ou Nada Confiante, com apenas cinco registos, revela que o ambiente online em si nada contribuiu para aumentar a confiança nas capacidades.

Relativamente às representações dos estudantes do curso de Educação Básica, verificámos nesta área sessenta e sete registos de tendência positiva $(+)$ e apenas três de tendência negativa (-).

\begin{tabular}{|c|c|c|l|}
\hline EST & UR & S & Registo \\
\hline EB2 & 7 & + & $\begin{array}{l}\text { O ambiente permitiu-me confiar mais nas minhas capacidades e expor sem receios as minhas ideias, pois, } \\
\text { como já referi, os temas discutidos talvez nós nunca tivéssemos pensado muito bem neles, mas depois de falar } \\
\text { neles nas aulas tornaram-se assunto de conversa mesmo nos intervalos. }\end{array}$ \\
\hline EB9 & 35 & - & $\begin{array}{l}\text { Posso, às vezes, não confiar muito nas minhas capacidades, mas nunca tive qualquer receio de expor as } \\
\text { minhas ideias, pelo que ainda não estou convencida que o ambiente online tenha realmente alterado esse } \\
\text { ponto de vista. }\end{array}$ \\
\hline
\end{tabular}

Quadro 5: Confiança nas Capacidades - Estudantes do Curso de Educação Básica.

Como podemos ver na primeira unidade de registo exemplificativa, o estudante - EB2 - refere que o ambiente online lhe permitiu confiar mais nas suas capacidades, expondo as suas ideias sem medos nem receios nas salas de aula virtuais.

Outros estudantes têm testemunhos idênticos:

EB10 - "A metodologia utilizada ajudou-me a ter mais confiança nas minhas capacidades, pois deu-me a oportunidade de expor as minhas ideias sem ser 'julgada' por isso. Penso que para esta UC este ambiente não podia ser melhor para nos ajudar a confiar nas nossas capacidades e expor as nossas ideias sem qualquer receio" (UR39).

EB11 - "A metodologia ajudou-me a expressar a minha opinião sem receio que os outros não concordassem comigo" (UR43).

EB22 - "A metodologia utilizada fez com que eu tivesse mais confiança nas minhas opiniões sem ter medo de divulgá-las a quem quisesse ler. Senti um grande àvontade. É, sem dúvida, uma forma de ensino muito diferente do que estamos habituados. Foi um aspeto muito positivo" (UR86).

EB30 - "Com esta UC ganhei um pouco mais de 'liberdade de expressão', isso é inquestionável. O facto de termos de expor as nossas ideias fez de mim uma pessoa bem mais confiante das minhas capacidades" (UR115).

Para além da questão da maior confiança nas capacidades, alguns estudantes sublinham que estes ambientes podem proporcionar uma sensação de maior segurança, porque as salas de aula virtuais (fóruns) não implicam "confrontos" verbais síncronos, o que, para quem é mais inibido, é um aspeto muito positivo:

EB37 - "Este ambiente permitiu-me confiar mais nas minhas capacidades e expor sem receio as minhas ideias, pois penso que o facto de não estarmos a falar para uma plateia cheia de gente e para um professor, e estarmos a escrever num computador sem estar ninguém presente nos relaxa mais e nos ajuda a aperfeiçoar o trabalho, pois não estamos sujeitos a pressões" (UR143).

EB40 - "Este ambiente tornou-me mais confiante, pois eu não gosto muito de expor as minhas ideias a uma grande 'plateia'. A utilização da plataforma ajudou-me bastante a expor as minhas ideias sem medos da reação dos outros, sem medo de estar a dizer algo errado" (UR155).

No entanto, é de registar que não existe unanimidade nas perceções dos estudantes do curso de Educação Básica, já que, como podemos observar na segunda unidade de registo exemplificativa do quadro anterior, a estudante EB9 refere que os seus índices de confiança não sofreram alterações com a lecionação da UC no ambiente online.

Também os estudantes do curso de Educação Física apresentam perceções semelhantes, registando-se nesta categoria quarenta e oito registos de tendência positiva $(+)$ e apenas dois registos de tendência negativa (-).

\begin{tabular}{|l|l|l|l|}
\hline EST & UR & S & Registo \\
\hline
\end{tabular}




\begin{tabular}{|c|c|c|l|l|}
\hline EF77 & 303 & + & $\begin{array}{l}\text { A metodologia usada permitiu que eu avaliasse as minhas capacidades e passei a confiar mais } \\
\text { nelas quando dava por mim a comentar temas pelos quais nunca me interessei e que desconhecia. }\end{array}$ \\
\hline EF97 & 390 & - & Nem sempre fui capaz de expor as minhas ideias, talvez com receio de que estas não fossem as mais corretas. \\
\hline
\end{tabular}

Quadro 6: Confiança nas Capacidades - Estudantes do Curso de Educação Física

Com efeito, como podemos ver na primeira unidade de registo exemplificativa (UR 303), o estudante considera que a metodologia utilizada lhe permitiu confiar mais nas suas capacidades, comentando, inclusive, temas em que não tinha interesse e que não o motivavam. Como podemos ler abaixo, é essa também a opinião da estudante EF87, ao afirmar que, à medida que foram decorrendo as atividades pedagógicas, foi ganhando mais confiança nas suas capacidades:

“(...) O início da UC foi complicado, mas, após ver a participação e empenho de todos os meus colegas nas salas de aula virtuais, a minha confiança cresceu e dei sempre a minha opinião" (UR350).

Para além da questão da maior confiança nas capacidades, o estudante EF106 sublinha também que este ambiente proporcionou o aumento da sua autoestima “(...) pela forma como consegui debater os temas que foram apresentados no decorrer dos módulos" (UR426).

Apenas dois testemunhos apontam no sentido contrário e, como podemos ler na segunda unidade de registo exemplificativa, o estudante EF97 refere que nem sempre conseguiu expor as suas ideias, porque os índices de confiança não seriam muito elevados.

Para este incremento na confiança nas capacidades, pensamos que o fórum de discussão online teve um papel determinante. Com efeito, esta ferramenta tem sido muito requerida por docentes que lecionam cursos em regime de blended learning que não dependem da proximidade física nem da resposta imediata [57]. Como verificámos pelo testemunho destes estudantes, esta ferramenta permitiu potenciar a troca de informação e discussão de assuntos de forma assíncrona e organizar debates de ideias com foco num tema preciso. Por ser assíncrono, possibilitou ao estudante consultar outras referências e ter tempo para refletir e enriquecer as suas intervenções, contribuindo assim, por um lado, para aumentar a confiança nas capacidades de cada um e, por outro, para favorecer a aprendizagem dos demais.

Finalmente, relativamente à quarta categoria, Relação com os Colegas, com cento e vinte registos, que se refere à forma como se estabelece a integração na comunidade virtual de aprendizagem e com a perceção de confiança recebida da comunidade, a classificação das unidades de registo, repartiu-se pelas frequências de Relação Fortalecida (+) e Relação Idêntica (-). A primeira, Relação Fortalecida, foi aquela que recebeu a maioria das referências, cento e dezassete registos, o que sugere, sem dúvida, que o ambiente de aprendizagem permitiu fortalecer os laços sociais entre os elementos da turma, formando uma comunidade de aprendizagem virtual; a segunda, Relação Idêntica, com apenas três registos, revela que o ambiente online não contribuiu para $\mathrm{o}$ fortalecimento de relações sociais com os colegas.

Relativamente às representações dos estudantes do curso de Educação Básica, verificámos nesta área sessenta e sete registos de tendência positiva $(+)$ e apenas três de tendência negativa (-).

\begin{tabular}{|c|c|c|c|}
\hline EST & UR & S & Registo \\
\hline EB7 & 28 & + & $\begin{array}{l}\text { Foi interessante conviver no espaço virtual com todos os colegas; esta diversidade de opiniões permitiu que } \\
\text { eu aprendesse muito; aprendemos muito uns com os outros, podia não haver concordância, mas havia uma } \\
\text { atitude educada e de respeito. Com isto, na minha opinião, todos tiveram uma relação virtual "saudável". }\end{array}$ \\
\hline EB9 & 36 & - & $\begin{array}{l}\text { Não considero que a metodologia aplicada me permitisse integrar-me melhor na turma, mas permitiu } \\
\text { certamente que eu ficasse a conhecer melhor os colegas e que tivesse uma opinião mais formada sobre eles. } \\
\text { Alguns colegas surpreenderam-me, pela positiva, com as suas participações. As temáticas estudadas foram, } \\
\text { por vezes, tema de conversa com alguns colegas. }\end{array}$ \\
\hline
\end{tabular}

Quadro 7: Relação com os Colegas - Estudantes do Curso de Educação Básica

Como podemos ver na primeira unidade de registo exemplificativa, o estudante EB7 refere que foi muito enriquecedor conviver com os colegas no espaço virtual, permitindo-lhe, por um lado, aprender bastante com eles e, por outro, estabelecer uma relação virtual muito "saudável". Outros estudantes sublinham as mesmas ideias:
EB10 - "Os debates nas aulas online ajudou-nos a ter uma boa relação; nós conseguimos dar a nossa opinião respeitando a dos outros e sem faltar ao respeito uns aos outros" (UR40).

EB11 - "Realmente acho que a relação da turma melhorou, acho que com estas aulas ficámo-nos a conhecer um pouco melhor" (UR44). 
EB24 - “A metodologia permitiu-me, através dos debates na plataforma, integrar-me melhor na turma, pois fui estabelecendo conversas com todas as pessoas da turma, deixei comentários na plataforma; todos iam dando a sua opinião, trocámos opiniões e perspetivas; conhecemos melhor o próximo e assim, perante esse conhecimento, já pudemos deduzir o comportamento dele em relação a certas temáticas" (UR94).

No entanto, registe-se que, apesar de não ser um testemunho que indica um mau relacionamento, a estudante EB9 refere, como podemos ver na segunda unidade de registo exemplificativa, que o ambiente online não contribuiu para uma melhor integração na turma. Acrescenta, contudo, que as discussões permitiram que conhecesse melhor os colegas, o que revela um posicionamento ambivalente nesta questão. Também os estudantes do curso de Educação Física apresentam perceções semelhantes, registando-se nesta categoria registos apenas de tendência positiva $(+)$.

\begin{tabular}{|l|c|c|c|}
\hline EST & UR & S & Registo \\
\hline EF79 & 310 & + & $\begin{array}{l}\text { Sem dúvida que a relação com os colegas foi "saudável"! Obtive reações de "vozes" contrárias à minha forma } \\
\text { de pensar (cada um no seu direito de expressão), algumas inclusive "fortes", mas que "aqueceram" o debate e } \\
\text { convidaram outros a opinar, mas que não me afastaram do grupo; também recebi comentários de incentivo } \\
\text { por parte de colegas que apreciaram a forma como expus os meus pensamentos e/ou ideais. Quer fosse pelas } \\
\text { opiniões duras e cruas que dei que não foram bem aceites, quer pelas ideias bem aceites e apoiadas que dei e } \\
\text { recebi, sou mais conhecida na turma do que os pastéis de Belém!! "Enturmadissíma"” e ainda bem! }\end{array}$ \\
\hline
\end{tabular}

Quadro 8: Relação com os Colegas - Estudantes do Curso de Educação Física

Com efeito, como podemos ver na unidade de registo exemplificativa (UR 310), a estudante considera que estabeleceu uma relação muito "saudável" com os colegas. Apesar da existência de uma pluralidade muito grande de opiniões, que "aqueceram" muitas vezes os debates, conseguiu sempre manter uma relação cordial com os diferentes elementos do grupo e integrar-se muito bem. Como podemos ler abaixo, é essa também a opinião do estudante EF82, que sublinha a questão da relação e da integração adequada no grupo:

"Penso que a metodologia utilizada me ajudou a integrar-me melhor na turma e a relacionar-me melhor com os outros; através da troca de ideias pude-me aperceber daquelas pessoas com as quais me identificava, visto partilhar as mesmas ideias; mesmo fora do ambiente escolar discutíamos ideias e opiniões sobre assuntos que abordávamos nas aulas" (UR322).

$\mathrm{Na}$ realidade, as salas de aula virtuais possibilitam diversos níveis de interação que vão desde o um para um até de muitos para muitos. Estes níveis estão presentes em diferentes áreas do ambiente online e assumem diferentes tarefas, recursos e funções sociais e educativas. As interações, não só com o professor, mas também com os colegas, configuram-se, pois, como a base prática da aprendizagem em ambiente e tais interações estão fundamentadas pelas teorias de carácter construtivista e sociointeracionista, como já referimos anteriormente, uma vez que exigem a negociação de conflitos e a partilha de significados [58].

\section{Conclusões}

A necessidade de acompanhar os desafios da sociedade contemporânea e, em parte, de dar resposta às atuais exigências que são feitas ao Ensino Superior fez com que a quase totalidade das instituições tenha adotado projetos de educação online, procurando integrar os ambientes virtuais de aprendizagem no processo pedagógico. Neste contexto, se aceitarmos que estes ambientes virtuais são ferramentas inovadoras para a criação de comunidades de aprendizagem, e que as dimensões psicológicas influenciam profundamente a nossa visão do mundo, então é crucial reconhecer uma nova perspetiva na criação de contextos de aprendizagem e reconhecer a necessidade do processo ser sustentado por modelos pedagógicos colaborativos, construtivistas e de aprendizagem pela descoberta que permitam ligar vários estilos de aprendizagem.

Baseados, pois, na necessidade de reconhecer esta nova perspetiva, desenvolvemos a nossa prática letiva ancorada num modelo de aprendizagem relacionado com o desenvolvimento de comunidades de prática e de aprendizagem e com a resolução de problemas. E os resultados dessa prática, tendo em conta as perceções dos atores envolvidos, revelam que, efetivamente, estes ambientes virtuais de aprendizagem podem ter efeitos muito positivos no autoconceito académico dos estudantes do ensino superior, em termos das diferentes categorias consideradas, quer seja a nível da sua motivação, da confiança nas suas capacidades, da 
organização das atividades ou da relação com os seus colegas.

Com efeito, pudemos concluir que os estudantes consideraram que o ambiente online "desenhado" pelo professor foi um fator motivacional determinante para $\mathrm{o}$ seu desempenho escolar. Ao destacarem a presença constante do professor nos diferentes espaços de comunicação do ambiente e os diferentes papéis assumidos (motivador, mediador, moderador...), ao salientarem a interação social existente entre estudantes e professor e entre pares e ao assumirem que este ambiente gerou discussões e conflitos cognitivos estimulantes, os estudantes acabam por revelar, indiretamente, que o modelo pedagógico proposto fez emergir uma comunidade de aprendizagem que os motivou para as atividades académicas da UC. Para além disso, é de destacar que os estudantes também referem os recursos audiovisuais disponibilizados como um elemento de motivação relevante. $\mathrm{Na}$ realidade, muitos autores reconhecem este poder motivador ao documento videográfico, porque este tipo de recurso pode lançar questões sobre determinado tema de impacto sobre os estudantes, apresentar testemunhos, fomentar reflexões e debates sobre notícias ou histórias ficcionais, entrevistas ou reportagens. O importante é que o recurso, enquanto elemento de motivação, catalise a sua atenção para determinado conteúdo e promova a reflexão que, por sua vez, conduza a aprendizagens partilhadas [47]. Alguns testemunhos do nosso estudo parecem apontar no sentido dessa aprendizagem partilhada.

Concluímos também que os estudantes consideram que se esforçaram por cumprir as tarefas solicitadas pelo professor no ambiente virtual e que o LMS é uma ferramenta que pode facilitar na organização e na gestão do tempo despendido na realização das atividades académicas. Estes são resultados que, de certa forma, não surpreendem, porque estes ambientes de e-Learning são normalmente espaços muito bem estruturados, delineados e organizados, que permitem aos intervenientes organizar-se em períodos temporais bem definidos.

No que diz respeito à questão da confiança nas suas capacidades, concluímos que o ambiente de aprendizagem tornou a maioria destes estudantes mais confiantes nas suas competências, e para essa confiança contribuíram, decisivamente, os fóruns de discussão online, que foram os espaços de discussão e comunicação por excelência da UC. Como verificámos, na opinião da maioria dos estudante, estes espaços permitiram a troca de informação e discussão de assuntos e propiciou a organização de debates de ideias com foco num tema preciso. Assim, este progresso na confiança das capacidades deve fazer-nos repensar e/ou redesenhar práticas tradicionalmente sedimentadas na sala de aula presencial. Enquanto ferramenta, como vimos, pode gerar maior participação e interação online, bem como ser fonte de estímulo e motivação. Cabe ao docente a responsabilidade de promover e intervir para sistematizar o seu uso, integrando-a como recurso pedagógico, a fim de criar condições para a construção do conhecimento, mas evitando a sensação de sobrecarga para o estudante e não exigindo muito mais tempo além do proposto [57].

Finalmente, relativamente à relação com os colegas, concluímos que este ambiente de aprendizagem permitiu fortalecer os laços sociais entre os elementos da turma, permitindo formar uma comunidade de aprendizagem virtual sólida.

Para a formação desta comunidade de prática foram decisivas as diferentes salas de aula virtuais criadas para o ambiente online. Estas salas de aula possibilitaram diversos níveis de interação, desde o um para um até de muitos para muitos. Para além disso, as interações, não só com o professor, mas também com os colegas, configuraram-se como a base prática da aprendizagem, e tais interações foram suportadas pelas teorias de carácter construtivista e sociointeracionista.

Terminamos referindo que, efetivamente, estes ambientes virtuais de aprendizagem permitem equacionar o processo pedagógico de forma diferente. No entanto, a mudança não deve ser vista só do ponto de vista tecnológico, mas também em termos de teoria e de prática. Estamos cientes de que esta mudança implica alterações culturais, pois obriga a repensar constantemente os papéis dos professores e dos estudantes e a relação existente entre eles, para além das implicações que devem ser concretizadas no plano da estruturação e planificação de cursos e currículos, sistemas de avaliação, formas de ensinar e aprender, metas a atingir. $\mathrm{O}$ nosso estudo, em particular, permite destacar a melhoria do autoconceito dos estudantes do ensino superior quando se recorre a um processo pedagógico sustentado em ambientes online. Os nossos resultados vão ao encontro de outros estudos [59], no que concerne à identificação das potencialidades dos ambientes online na aprendizagem, no desenvolvimento de competências sociais e cognitivas, a partir da opinião dos próprios atores. As dimensões do autoconceito académico por nós analisadas articulam-se com a autoperceção dos estudantes em termos de envolvimento nas tarefas, do sentido da autocompetência e expectativas de as cumprir e, ainda, em termos das dimensões sustentadas nas referidas competências sociais e cognitivas.

\section{Referências}

[1] D. Garrison, T. Anderson, W. Archer. Critical Inquiry in a Text- Based Environment: Computer Conferencing in Higher Education. The Internet and Higher Education, 2 (2-3): 87-105, 2000. 
[2] A. Monteiro. O currículo e a prática pedagógica com recurso ao b-learning no ensino superior. Tese de Doutoramento em Ciências da educação, Universidade do Porto, Janeiro 2011.

[3] A. Monteiro. O processo de Bolonha e o trabalho pedagógico em plataformas digitais: possíveis implicações. In A. Monteiro, J. A. Moreira, A. C. Almeida (orgs.) Educação Online: Pedagogia e Aprendizagem em Plataformas Digitais, páginas 15-26, De Facto Editores, Santo Tirso, 2012.

[4] P. Anderson. What is web 2.0? Ideas, technologies and implications for education. Bristol: JISC, 2007.

[5] L. Santos, Almeida, L. Vivências académicas e rendimento escolar: Estudo com alunos universitários do $1 .^{\circ}$ ano. Análise Psicológica, 2 (XIX): 205-217, 2001.

[6] J. Tavares. Factores de sucesso/insucesso no $1 .^{\circ}$ ano dos cursos de Licenciatura em Ciências e Engenharia do Ensino Superior. In A. Soares, A. Osório, J. Capela, L. Almeida, R. Vasconcelos, S. Caires (eds.) Transição para o Ensino Superior, páginas 23-34, APPORT, Braga, 2000.

[7] J. Tavares, I. Silva. Sucesso académico no ensino superior. In R. Sousa, E. Sousa, F. Lemos, C. Januário, (orgs.) III Simpósio Pedagogia na Universidade, páginas 323-347, Reitoria da Universidade Técnica de Lisboa, Lisboa, 2001.

[8] L. Faria, A. Fontaine. Estudo de adaptação do Self Description Questionnaire III (SDQ III) a estudantes universitários portugueses. Psychologica, 8: 41-49, 1992.

[9] I. Janeiro, J. Marques. Auto-estima e atitudes de planeamento e de exploração da carreira em jovens do $9 .^{\circ}$ e $11 .^{\circ}$ anos. Revista Portuguesa de Psicologia, 34: 83-99, 1999.

[10] M. Simões, A. Serra. A importância do autoconceito na aprendizagem escolar. Revista Portuguesa de Pedagogia, 21: 233-252, 1987.

[11] J. Stocker, L. Faria, L. Auto-conceito e Adaptação ao Ensino Superior. In $X$ Congresso Internacional Galego-Português de Psicopedagogia, páginas 30-43, 2009.

[12] I. Valente, I. Auto-conceito em estudantes de enfermagem. Quarteto, Coimbra, 2002.

[13] F. Veiga, H. Moura. Disrupção escolar e auto- conceito dos jovens. Jornal de Psicologia, 11: 34, 15-21, 1993.

[14] G. Seco. O auto-conceito escolar em educadoras de infância: um estudo transversal. Revista Portuguesa de Pedagogia, 1: 119-139, 1993.

[15] B. Byrne. The general/academic self-concept nomological network: A review of construct validation research. Review of Educational Research, 54 (3): 427-456, 1984.

[16] R. Shavelson, J. Hubner, G. Stanton. Selfconcept: validation of construt interpretations. Review of Educational Research, 46 (3): 407441, 1976.

[17] J. Willis, L. F. Campbell. Exercise psychology. Champaign. Human Kinetics Publishers: Illinois, 1992.

[18] S. Harter, S. Manual for the self-perception profile for children. University of Denver: Denver, 1985.

[19] J. Fleming, B. Courtney. The dimensionality of self-esteem: hierarchical facet model for revised measurement scales. Journal of Personality and Social Psychology, 46 (2): 404-421, 1984.

[20] H. Marsh, J. Hattie, J. Theoretical perspectives on the structure of self-concept. John Willey \& Sons: New York, 1996

[21] J. Costa. Auto-conceito: Da diversidade conceptual à relação com o desempenho académico. Revista Portuguesa de Pedagogia, 2: 103-136, 2001.

[22] H. Marsh. Age and sex effects in multiple dimensions of self-concept: Preadolescence to early adulthood. Journal of Educational Psychology, 81: 417-430, 1989.

[23] H. Marsh. Using the national longitudinal study of 1988 to evaluate theoretical models of self concept: The Self-description Questionnaire. Journal of Educational Psychology, 86, 3: 439456, 1994.

[24] H. Marsh. The importance of being important Theoretical models of relations between specific and global components of physical self concept. Journal of Sport \& Exercise Psychology, 16: 306-325, 1994.

[25] F. Peixoto, L. Almeida, L. A Organização do Autoconceito: Análise da Estrutura Hierárquica em Adolescentes. Psicologia: Reflexão e Crítica 
3: 533-541, 2011.

[26] C. Estêvão, L. Almeida. Prática desportiva e medidas de autoconceito físico e académico. In L. S. Almeida, M. J. Gomes, P. B. Albuquerque, S. G. Caires (Eds.), Actas do IV Congresso Galaico-Português de Psicopedagogia, páginas 512-519, Universidade do Minho, Braga, 1998.

[27] M. Lima, G. Seco. Autoconceito académico em adultos. Revista Portuguesa de Pedagogia, 24: 303-315, 1990.

[28] L. Faria, N. Lima. Auto-conceito académico, social e global em estudantes universitários. Revista da Faculdade de Ciências Humanas e Sociais, 3: 225-235, 2006.

[29] J. Chapman, F. Boersma. Affective correlates of learning disabilities. Lisse Swets \& Zeithinger: The Netherlands, 1980.

[30] R. Burns. Self-concept. development and education. Holt, Rinehardt and Winston: London, 1982.

[31] D. Urhahne, S. Chao, M. Florineth, S. Luttenberger, M. Paechter. Academic self-concept, learning motivation, and test anxiety of the underestimated student. British Journal of Educational Psychology, 81: 161-177, 2011.

[32] R. Burns. The self-concept in theory, measurement, development and behaviour. Longman Group Limited: New York, 1979.

[33] F. Bento, F. Autoconceito e participação social do estudante do ensino superior. Dissertação de Mestrado, Universidade de Coimbra, Coimbra, 1997.

[34] D. Garrison, T. Anderson. El e-learning en el siglo XXI. Investigación e práctica. Octaedro: Barcelona, 2005.

[35] L. Cohen, L. Manion. Métodos de Investigation Educativa. La Muralla: Madrid, 1990.

[36] J. Pujadas Munoz, J. El método biográfico: el uso de las histórias de vida en ciências sociales. CIS: Madrid, 1992.

[37] O. Holsti, O. Content analysis for the social sciences and humanities. Addison Wesley Hill: Boston, 1969.

[38] B. Berelson. Content analysis in Communication Research. Hafner Publ. Co: New York, 1971.

[39] L. Bardin, L. L'analyse de contenu. PUF: Paris, 1977.
[40] K. Krippendorf. Content analysis. Sage: London, 1980.

[41] F. Ferrarotti. Sociologia. Editorial Teorema: Lisboa, 1986.

[42] J. Vala. A análise de conteúdo. In A. Silva, J. Pinto, J. (orgs.), Metodologia das Ciências Sociais, páginas 63-81, Edições afrontamento, Porto, 1986.

[43] F. Veiga. Estudo de um instrumento de autoconceito escolar. In M. Gonçalves, I. Ribeiro, S. Araújo, C. Machado, L. Almeida, M. Simões (Eds.), Avaliação Psicológica: Formas e Contextos, páginas 365-380, APPORT, Braga,1996.

[44] M. Miles, A. Huberman, A. Drawing valid meaning from qualitative data: toward a shared craft. Educational Researcher, 13 (5): 20-30, 1984.

[45] M. Goulão. Ensinar e aprender em ambientes online: alterações e continuidades na(s) prática(s) docente(s). In J. A. Moreira, A. Monteiro (orgs.), Ensinar e aprender online com tecnologias digitais, páginas 15-30, Porto Editora, Porto, 2012.

[46] J. A. Moreira, A. Monteiro. O Trabalho Pedagógico em Cenários Presenciais e Virtuais no Ensino Superior. Educação, Formação \& Tecnologias, 3 (2): 82-94, 2010.

[47] J. A. Moreira. (Re) Pensar o ensino com objetos de aprendizagem audiovisuais em ambientes presenciais e online. In J. A. Moreira, A. Monteiro (orgs.), Ensinar e aprender online com tecnologias digitais, páginas 77-98, Porto Editora, Porto, 2012.

[48] J. A. Moreira. Cinema na escola: prazer e aprendizagem em ambientes virtuais. Imagens $d a$ Cultura. Cultura das Imagens, 1 (2): 173-181, 2012.

[49] J. A. Moreira, A. Monteiro. Exploração Didática de Filmes Educativos em Ambientes Virtuais de Aprendizagem. Cadernos de Pedagogia no Ensino Superior, 21: 3-14, 2012.

[50] J. Moran. Leituras dos Meios de Comunicação. Ed. Pancast: São Paulo, 1993.

[51] J. Ferrés. Vídeo e Educação. Artes Médicas: Porto Alegre, 1996.

[52] A. Bartolomé. Nuevas Tecnologias en el aula. Grao: Barcelona, 1999. 
[53] J. Moran, J. Novas Tecnologias e Mediação Pedagógica (5. ${ }^{a}$ ed.). Papirus: Campinas, 2002.

[54] S. Amaral. Serviço de apoio a distância ao professor em sala de aula pela tv digital interativa. Revista Digital de Bibliotecomonia e Ciência da Informação, 1 (2): 37-54, 2004.

[55] J. A. Moreira, A. G. Ferreira, A. Almeida. Communities of Inquiry em Blended Learning. In A. Monteiro, J. A. Moreira, A. Almeida, J. A. Lencastre (coord.). Blended Learning em Contexto Educativo: Perspetivas teóricas e práticas de investigação, páginas 97-132, De Facto Editores, Santo Tirso, 2012.

[56] A. Monteiro, J. A. Moreira. O b-learning no Ensino Superior. Reflexões em torno de práticas. Cadernos de Pedagogia no Ensino Superior, 20: 23-36, 2012.

[57] A. Monteiro, J. Lencastre, J. A. Moreira. Interação em Salas de Aula Virtuais. In A. Monteiro, J. A. Moreira, A. Almeida, J. Lencastre (coord.). Blended Learning em Contexto Educativo, páginas 81-98, De Facto Editores: Santo Tirso, 2012.

[58] A. Monteiro, J. A. Moreira. O Blended Learning e a Integração de Sujeitos, Tecnologias, Modelos e Estratégias de Ensino-aprendizagem. In A. Monteiro, J. A. Moreira, A. Almeida, J. A. Lencastre (coord.). Blended Learning em Contexto Educativo, páginas 33-58, De Facto Editores, Santo Tirso, 2012.

[59] A. Monteiro, R. Barros. O Blended Learning no Ensino Superior: a perceção dos estudantes. In A. Monteiro, J. A. Moreira, A. C. Almeida \& J. A. Lencastre (coord.). Blended Learning em Contexto Educativo, páginas 135-150, De Facto Editores: Santo Tirso, 2012. 